\section{SUGAR: WHAT CAN WE LEARN FROM THE ANTI-SMOKING CAMPAIGN?}

$\mathrm{E}$ xtra! Extra! Read all about it! 'Sugar is as dangerous as tobacco'; 'Sugar is the new tobacco'. These recent headlines are old news as far as dental professionals are concerned. Unfortunately, as we so often see, people take more notice when the message concerns how long they might live.

Like smoking, sugar certainly does have an instant effect on teeth. Research is also showing us that excessive sugar consumption is having a major impact on obesity levels which lead to heart problems and premature death. But how accurate is the claim that sugar is the new tobacco? And what can be learnt from the anti-smoking lobby to help us to change the public's perception of sugar?

We don't need tobacco; do we need sugar? Sugar was once a luxury reserved for the rich. Our consumption of sugar may have increased by $31 \%$ in the last few decades but we don't actually need it. Scientists agree that it is an entirely unnecessary food. Is sugar addictive like nicotine? Though there is no current evidence to indicate that this is the case, Chief Medical Officer, Dame Sally Davies, said recently that she thinks that researchers will find that it is. Studies have shown that foods high in fat and sugar can boost dopamine levels to trigger our reward systems just as addictive drugs do. However, officially there is no current conclusive evidence that sugar is addictive.

One of the key differences between sugar and tobacco is that sugar does not have a passive effect as smoking does. However, on the whole we dictate what our children eat so in that sense sugar is generally imposed on children. If sugar is proven to be addictive then a laissez faire attitude towards sugar from adults could be condemning children to a lifetime of dental caries, health problems due to obesity and even premature death.

Many factors contributed to the public change in attitude towards smoking and it is clear that it takes time not only to change the public perception but also government policies, particularly considering the lobbying power of big business. Laws, scientific evidence, advertising regulation, health education and the media have all contributed to the reduction in smoking prevalence in the UK since the 1950s. So far we have only seen the beginning of what could ultimately be a revolution in sugar consumption. The media have listened but will the food industry make the necessary changes? Or will we have to resort to regulation, tax and legislation to drastically alter people's perception of sugar?

The story of salt reduction will likely serve as a better comparison for sugar than tobacco. The people behind 'Action on Sugar' launched earlier this year are the same as those behind the successful Consensus Action on Salt and Health (CASH) campaign in the 1990s. CASH was set up in 1996 in response to a Committee on Medical Aspects of Food and Nutrition Policy (COMA) report advising that to salt levels in foods should be reduced. At the time, the Chief Medical Officer refused

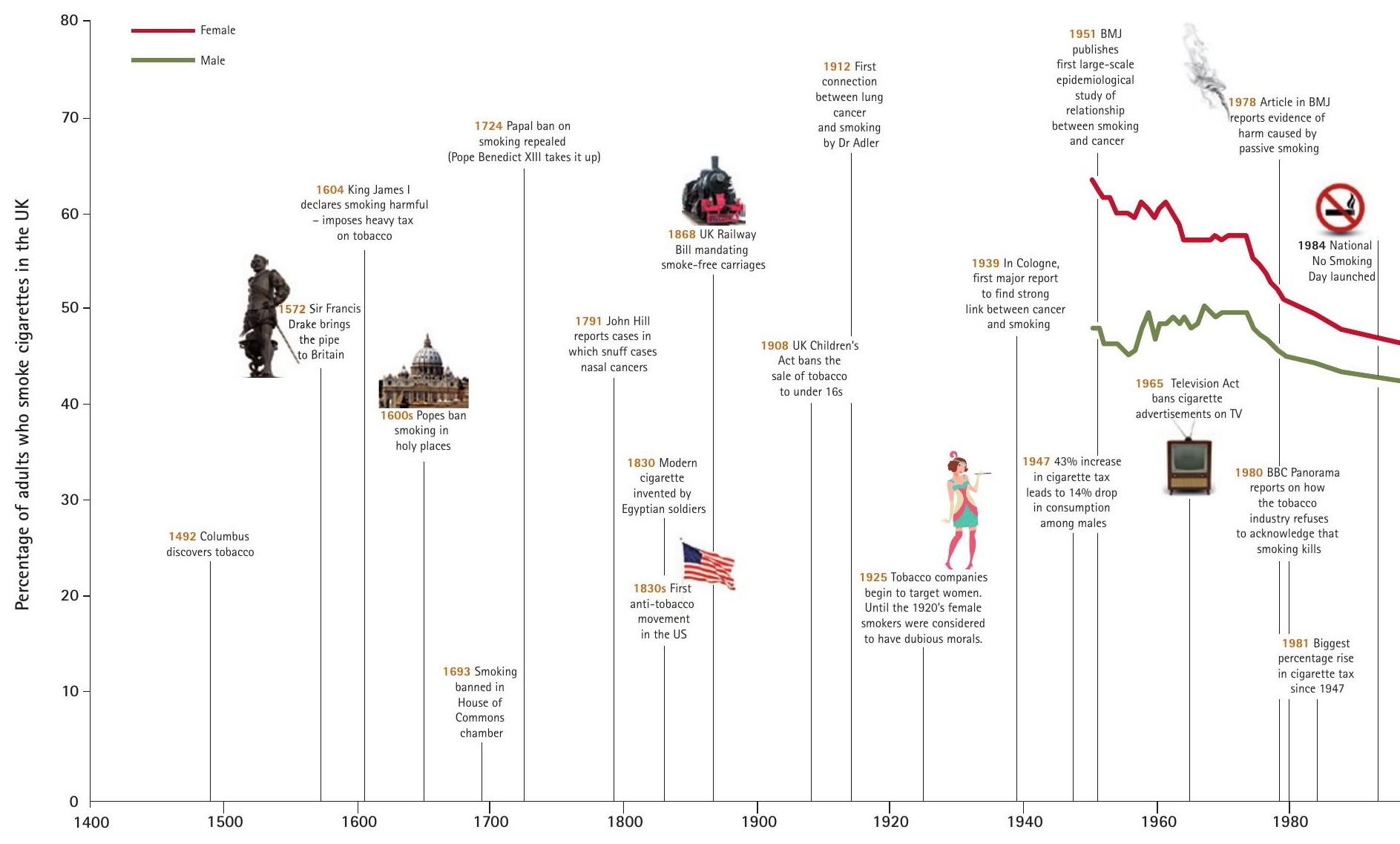

Tobacco timeline information selected from Key dates in the history of anti-tobacco campaigning produced by ash (action on smoking and health). A much more comprehensive list can be found in the original document on the ash website: http://www.ash.org.uk/ Smoking prevalence statistics from Cancer Research UK www.cancerresearchuk.org/cancer-info/cancerstats/types/lung/smoking/lung-cancer-and-smoking-statistics 
